N

O

T

A

S 


\section{RORTY Y EL PRAGMATISMO}

Gabriel Bello Reguera

Universidad de La Laguna

\section{Introducción}

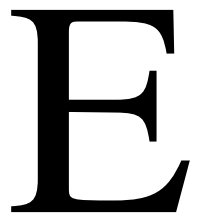

ntre los diez filósofos elegidos para este curso, R. Rorty es el único norteamericano entre nueve europeos (Nietzsche, Husserl, Wittgenstein, Heidegger, Ortega, Russel, Sartre, Gadamer y Habermas) ${ }^{1}$. Cuando, por su parte, nombra Rorty a los tres filósofos más importantes de este siglo, coincide con los organizadores de este curso, en la valoración alta de dos de éllos, Heidegger y Wittgenstein, a los que añade a su compatriota e inspirador J. Dewey. En la lista de aquí la ventaja de Europa sobre Norteamérica es de 9 á 1. En la de Rorty de 2 á 1 . Sirva este apunte de competición deportiva como un síntoma de la tensión crítica entre la filosofía europea y la norteamericana.

La obra de Rorty es voluminosa y la bibliografía sobre élla practicamente inabarcable. En un contexto como éste, he optado por dividir mi intervención en dos partes. La primera tratará de esbozar el contexto en el que se gesta y desarrolla la obra. En la segunda intentaré sugerir lo que a mi parece el núcleo teórico de la misma.

\section{El contexto}

La formación de R. Rorty tiene lugar en el cruce del pragmatismo norteamericano con el neopositivismo y la filosofía analítica de origen europeo. A partir de ahí él ha ido elaborando una obra, aun viva y abierta, muy abierta, que ha logrado crear un clima conocido como neopragmatismo, cuyo contexto histórico y cultural convendría sugerir. Me voy a limitar al componente pragmatista pues la filosofía analítica ha estado más presente en nuestro pasado reciente.

1 «Diez filósofos del Siglo XX» Organizado por el Aula Jorge Juan y el ICE de la Universidad de Alicante en el curso 1999-2000, dirigido por el Prof. Manuel Atienza, en cuyo contexto se presentó, como conferencia, este ensayo. Mantiene su forma original salvo algún detalle de redacción y algún añadido bibliográfico. 
El pragmatismo norteamericano clásico nació del intento de articular filosoficamente la cultura norteamericana cuando Norteamérica se estaba convirtiendo en una Gran Sociedad y, más aún, en Gran Potencia Imperial, cristalizada en 1898 a expensas del Imperio Español, al que puso fin en $\mathrm{Cu}-$ ba y Filipinas (uno de los pragmatistas clásicos, W. James, hermano del novelista $\mathrm{H}$. James, fué antibelicista en aquella ocasión). Con todo, en aquel momento la Sede Imperial seguía estando en Europa: el Imperio Británico, cuya cultura se proyectaba, con la alemana, poderosamente sobre una Norteamérica culturalmente aún adolescente.

Esta génesis histórica del pragmatismo marcará dos de sus rasgos identificatorios. El primero es su orientación preferentemente práctica, hacia una ética y una política democráticas, en contraste con el teoreticismo de la filosofía europea, dependiente de la noción griega de la «teoría» como contemplación, surgida y desarrollada mayormente en sociedades predemocráticas. El segundo, por su parte, es el que hubiera de construir y reconstruir su identidad filosofífica en diálogo crítico con la filosofía europea, sobre todo la moderna ${ }^{2}$ : el idealismo alemán mezclado con un cierto transcendentalismo teológico, el empirismo ingles, y el racionalismo cartesiano francés. Este nacimiento crítico -y no metafísico, dogmático- constituye la labor de los pragmatistas clásicos: Peirce, James, Royce, Mead y Dewey, en mayor o menor medida.

El diálogo con la filosofía europea pasa, hasta incluir a Rorty, por las siguientes fases hasta.

Una primera de formación, en la que Charles S. Peirce (1839-1914) no sólo se enfrenta al cartesianismo, al idealismo y al empirismo, sino también y al socialdarwinismo de H. Spencer, una adaptación de la teoría biológica de Darwin de la supervivencia del más apto para justificar la desigualdad socio-económica y política. A partir de Peirce, el darwinismo constitituirá una de las señas de identidad del pragmatismo hasta Rorty ${ }^{3}$. La contribución más sobresaliente de Peirce es la creación de la orientada en sentido pragmático. Esta es la verdadera raíz del pragmatismo.

La segunda fase es de desarrollo, difusión y expansión. Primero a cargo de W. James (1842-1910) y después de J. Dewey (1859-1952), pero cuyo apogeo cubrió los años que van desde finales del s. XIX hasta la Segunda Guerra Mundial. El caballo de batalla es el concepto clásico de verdad, como correspondencia con la realidad. Peirce lo redefine en términos consen-

\footnotetext{
${ }^{2}$ Por lo cual yo tiendo a pensar que en el pragmatismo hay un elemento poderosamente postmoderno.

${ }^{3}$ R. Rorty, «Dewey, Between Hegel and Darwin», en H.J. Saatkamp, Jr., Rorty. The Philosopher Responds to His Critics, Nasville/Londres, Vanderbildt Univ Press, 1995.
} 
suales y James utilitaristas, lo cual habría de suscitar las críticas de, entre otros, B. Russell y E. Durkheim ${ }^{4}$. Es la época de la primera ola influencia del pragmatismo en Europa: Schiller (Inglaterra), Sorel (Francia), Papini (Italia), y, en alguna medida, Ortega y Gasset (España). La polémica revive durante los años veinte y treinta del S. XX entre Russell y Dewey siempre al propósito del problema de la verdad. Russell -en un momento en que el imperialismo norteamericano, ascendente, desafía al inglés, decadentetiende a dar del pragmatismo una versión despectiva: como una filosofía del interés práctico inmediato, político y económico, comercial. Dewey, por su parte, lo ridiculiza. Es - dice- como asociar la filosofía francesa a la costumbre gala de tener una amante además de una esposa, o como asimilar la filosofía alemana a un combinado de cerveza y salchicha.

Durante esta misma década -años treinta- tienen lugar dos episodios que afectan al pragmatismo de forma desigual. Uno es la llegada a Norteamérica de algunos miembros del Círculo de Viena, cuyo positivismo lógico-analítico habría de llegar a desplazar a un pragmatismo que, con Dewey, se había convertido en abiertamente político, democrático, dentro de una cierta tosquedad lógica (para el paladar neopositivista epistemológicamente centrado). Como contrapartida, sin embargo, entre 1931 y 1935, tiene lugar la publicación de los Collected Papers de Peirce ${ }^{5}$, semi-olvidado hasta entonces, lo cual supone la aparición del punto de vista pragmático en el análisis del lenguaje que acabará por imponerse al lógico-empírico de los neopositivistas.

La tercera fase se abre al final de la segunda guerra mundial, y se articula, asímismo, en torno a dos episodios. Por un lado, la presencia de la Escuela de Frankfurt en Norteamérica -huyendo del nazismo- está en el origen de la Crítica de la razón instrumental ${ }^{6}$ - donde M. Horkheimer, en la línea de Russell, vuelve a la carga contra Dewey y su instrumentalismo: por

\footnotetext{
${ }^{4}$ B. Russell, «The Transatlantic Truth», en The Albany Review, Enero de 1908, y «Pragmatism», en The Edinburgh Review, Abril de 1909. Ambos están recogidos en Los problemas de la filosofía, Madrid, Alianza, 1968 (or. ing., 1966) donde se puede leer: «La novedad esencial del pragmatismo está en que admite, como base para la creencia cualquier clase de satisfacción que pueda derivarse de mantenerla, y no simplemente la satisfacción teorética que la ciencia busca [...] por eso se adapta igualmente bien a la democracia en el interior y al imperialismo en el exterior» (pp. 136 y 157). ¿No era eso lo que venía ocurriendo en Inglaterra donde se mantenía la exigente satisfacción teorética de Russell? E. Durkheim, Pragmatismo y sociología, Buenos Aires, Schapire, s/f. Según el prologuista, el texto original procede de un curso que dió Durkheim entre 1913 y 1914, justo antes de la guerra, con el objetivo de «hacer conocer a los estudiantes esa forma todavía nueva del pensamiento filosófico: el Pragmatismo» (p. 7).

5 Collected Papers of Charles Sanders Peirce, Vols. I-VI., ed. por C. Hasthorne y P. Weiss, Cambrigde, Mass., Harvard University Press, 1931-1935.

${ }^{6}$ Buenos Aires, Sur, 1973 (or. al., 1967).
} 
carecer de criterios críticos sustantivos. El instrumentalismo mantiene, en línea con su inspiración darwinista, que las teorías filosóficas y científicas son instrumentos para adaptarnos a la realidad en lugar de formas de conocer (y almacenar) la realidad en un lenguaje verdadero o racional. Si, a juicio de Russell, el pragmatismo cojeaba por la verdad, al de Hokheimer lo hace por la racionalidad. Aunque, de hecho, lo que aparece en su texto es, más que la racionalidad misma, su nostalgia, que Habermas tratará de remediar al redefinir la racionalidad, en los años setenta -paradojicamente en la estela del pragmatismo: el de Peirce-, en términos pragmático-comunicativos. Como se sabe, la crítica de Horkheimer al instrumentalismo de Dewey se hace extensiva, con Adorno, a la cultura norteamericana como «industria cultural», que alimenta la imagen francfurtiana de la «racionalidad intrumental» o la «unidimensionalidad».

El segundo episodio de esta tercera fase tiene un sentido diferente. $\mathrm{Me}$ refiero, ahora, a la recepción en Norteamérica de los Collected Papers de Peirce, uno de cuyos efectos es la articulación de la de la pragmática como un enfoque del lenguaje nuevo y autónomo, más allá del compromiso formalista y epistemologista del neopositivismo. Es el caso de Ch. Morris cuyo libro Signos, lenguaje y conducta, publicado en 1946, operó durante mucho tiempo como referencia obligada. Aunque, por mi parte, prefiero Ethics and Language, de Ch. Stevenson, aparecido en 1944, que tendrá una amplia recepción crítica, desde posiciones aún neopositivistas, en la Inglaterra de los años cincuenta y sesenta. Esta crítica habría de ser recuperada, en los ochenta por A. McIntyre en su justamente famoso Tras la virtud ${ }^{7}$-. McIntyre ve en Stevenson la articulación filosófica más solvente del emotivismo ético que, en su lectura, funciona como una especie de cable cuyos gruesos hilos son: Nietzsche y el vitalismo, Weber y su politeismo de los valores, Sartre y el existencialismo, y el narcisismo esteticista contemporáneo, cuyo pluralismo diferencialista vuelve imposible un razonamiento moral concluyente y unificado. Creo, por mi parte, que cabe otra lectura de Stevenson. Como la del iniciador del análisis pragmático del lenguaje moral, un punto de no retorno en la reflexión (meta)ética, sobre todo al ser reforzado por la obra del segundo Wittgenstein y de Austin y los múltiples herederos de ambos, más o menos críticos. Más como K. O. Apel, J. Habermas, y -desde otro lado- J. Derrida. Menos como el propio Rorty o J.F. Lyotard.

La decada de los setenta daría lugar a una cuarta fase que, como las anteriores, opera en un doble sentido. Casi a comienzos de la década, en 1973, Apel propone una lectura de Peirce como alguien que, al final del S. XIX, llevó a cabo la transformación semiótica de la filosofía transcedental ale-

\footnotetext{
${ }^{7}$ Barcelona, Crítica, 1987 (or. nort., 1984). Ver, por ejemplo la segunda mitad del cap. 2.
} 
mana: la sustitución de las ideas por los signos como objetos primarios de la filosofía y, coherentemente, la sustitución de la conciencia por la comunidad como intérprete de los mismos ${ }^{8}$. Este gesto de Apel constituye, desde el corazón filosófico de Europa, toda una consgración histórica del pragmatismo, el movimiento filosófico genuinamente norteamericano. Pero Apel cobra un peaje por este reconocimiento: la transcedentalización de la semiótica en la dirección de una «pragmática transcendental»; aplicar a la experiencia semiótico-comunicativa, intersubjetiva, el método de análisis transcendental o reconstrucción de sus condiciones a priori de posibilidad, que Kant había aplicado a la experiencia cognitiva y moral, subjetiva. De aquí saldrá, asímismo, la pragmática universal de Habermas, quien, andando el tiempo, invocará la antropología semiótica de otro pragmatista clásico, G.H. Mead, como uno de los ingrediantes de su pensamiento postmetafísico 9 . Sea cual sea el balance final, la obra de Apel y Habermas, dos de los filósofos más influyentes del las últimas décadas del siglo XX, no sería lo que es sin la vigorosa influencia de la semiótica pragmática o del pragmatismo semiótico de Peirce.

El segundo episodio de esta cuarta fase tendrá lugar al final de la década. En 1979, entra en escena R. Rorty con su La filosofía y el espejo de la naturalez $a^{10}$, justo en la dirección contraria de Apel y Habermas. Y de Peirce, a quien él sustituye como héroe filosófico por Dewey (además de Wittgenstein y Heidegger). Lo que Rorty cree llevar a cabo es la sustitución de la epistemología y su operación canónica, la conmensuración con un lenguaje originario, que opera como espejo de la naturaleza, incluida la naturaleza humana, el yo, por la hermenéutica y su procedimiento típico, la conversación de efectos no cognitivos sino edificantes. Esta sustitución implica una tarea doble y complementaria. Por un lado, la deconstrucción de la filosofía moderna, de orientación cognitivo-epistémica, a partir de Descartes, Locke y Kant, incluída la filosofía analítica del lenguaje, cuya crítica ya había llevado a cabo en su Introducción a El giro lingüístico ${ }^{11}$ - . Rorty cree que este tipo de filosofía ha ocupado masivamente -y esterilizado- los departamentos de Filosofía norteamericanos, pero en autores como Quine

${ }^{8}$ K.O. Apel, «De Kant a Peirce: la transformación semiótica de la filosofía transcendental», en su La transformación de la filosofía, Madrid, Taurus, 1985, Vol. II.

9 J. Habermas, Pensamiento postmetafísico, Madrid, Taurus, 1990 (ed.al., 1988), III.8: «Individuación por vía de socialización. Sobre la teoría de la subjetividad de G.H. Mead».

${ }^{10}$ Madrid, Cátedra, 1983; original norteamericano, Philosophy and the Mirror of Nature, New Jersey, Princeton University Press, 1979.

${ }^{11}$ R. Rorty, comp., The Lingüístic Turn: Recent Essays in Philosophical Method, Chicago, University of Chicago Press, 1967. La versión castellana, a mi cargo, de la Introducción a este volumen puede verse en R. Rorty, El giro lingüístico, Barcelona, Paidós, 1990. 
(discípulo de Carnap pero también de Dewey), Sellars, y Davidson conserva ciertos elementos pragmátistas que él, Rorty, trata de recuperar y reforzar. La segunda tarea -su objetivo básico- es la recuperación la inspiración ética y política del pragmatismo clásico. Aquí es donde Rorty trata de conectar a Dewey con una amplia corriente europea en la que caben el Wittgenstein de las formas de vida y los juegos de lenguaje, y la tradición hermenéutico-existencial, de Sartre a Gadamer, a quienes asocia desprejuiciadamente en el cap. VIII, con el mismo propósito de sustituir la epistemología por una hermenéutica, y la filosofía sistemática por una filosofía edificante.

Estos puntos de vista serán ampliados y reafirmados en Las consecuencias del pragmatismo ${ }^{12}$ donde la figura de Dewey cobra mayor relieve, pero también suscita una enorme polémica entre los eruditos del pragmatismo clásico. Lo mismo que ocurre con Heidegger, Derrida o Foucault -siempre un escalón por debajo de su admirado Dewey- entre los lectores de ambos. El efecto más duradero de este libro es que, a partir de entonces, Dewey es una figura revalorizada tanto dentro como fuera de Norteamérica como un clásico del liberalismo y la democracia (a lo cual ha contribuído la caída histórica de las dictaduras socialistas). A partir de entonces, Rorty ha dedicado su atención, cada vez más, a una mezcla de ética y política que no es otra cosa que una «ética democrática», desde una orientación esteticista que le ha vuelto a colocar en el ojo de la crítica. El núcleo de esta preocupación es el libro Contingencia, ironía y solidaridad ${ }^{13}$ con el que (según confesión propia) hacia 1992/93 había consegido vender un enorme número de copias y acumular un inmenso volumen de críticas. Con posterioridad, Rorty ha publicado tres volúmenes de Philosophical Papers que recogen la mayoría de sus escritos de las décadas $80 / 90^{14}$.

Cerraré esta primera parte, con un par de observaciones sobre el pragmatismo en su conjunto, incluído Rorty.

La sustitución -en primer lugar- de la Metafísica por la ciencia. Más en concreto, de la metafísica hegeliana de la historia por la Biología evolutiva de Darwin. La consecuencia inmediata es la sustitución de la necesidad de las leyes de la historia por el azar y la contingencia de las relaciones con el

${ }_{12}$ Vers. cast. (Madrid, Tecnos, 1997) de Consequences of Pragmatism, Minneapolis, University of Minnesota Press, 1982.

${ }_{13}$ Versión cast. (Barcelona, Paidós, 1990) de Contingency, Irony and Solidarity, Nueva York, Cambridge University Press, 1989.

${ }_{14}$ Me refiero a Objectivity, Relativism and Truth. Philosophical Papers 1, Cambridge, Cambridge University Press, 1991 (vers. cast., Barcelona, Paidós, 1996). Essays on Heidegger and Others. Philosophical Papers 2., Cambridge, Cambridge University Press, 1991 (vers. cast., Barcelona, Paidós, 199), y Truth and Progress. Philosophical Papers, 3., Cambridge, Cambridge University Press, 1998 (vers, cast., Barcelona, Paidós, 2000). 
medio, un medio humano, cultural y ligüístico, no ya natural al estilo de las otras especies animales. Un medio que transforma la causalidad biológica en causalidad semiótica. He denominado ${ }^{15}$ a esta imagen del mundo, alternativa a la filosofía de la historia, «darwinismo semiótico», cuyo órgano de adaptación es la significación. Palabra, ésta -«significación»- cuyo significado es el intercambio entre interlocutores de signos lingüísticos con sus correspondientes efectos semióticos. Según autores e interpretaciones, el intercambio lingüístico oscila entre el lenguaje científico y su estructura lógico empírica, y el lenguaje conversacional ordinario, cuya estructura es más bien narrativa. Desde esta perspectiva, el lenguaje científico no es más que una especialización de la semiótica, y la comunidad de investigación un condesado de la más amplia y extensa «comunidad de conversación», de condición ética y política, formadora de las identidades democráticas. No otra es la significación profunda del giro lingüístico-pragmático.

De donde el segundo rasgo.

Se trata, ahora, de la sustitución de la perspectiva teoreticista clásica -teoría como «contemplación»- por una orientación eminentemente práctica, ética y política, fundidas ambas en una teoría de la democracia, cuya inspiración Rorty ha encontrado en Dewey y, últimanente, también en Whitman y, más allá aún, en Emerson ${ }^{16}$. Esta inspiración es utilizada por Rorty con triple propósito: recuperar el orgullo norteamericano después de la humillación de Vietnam, tanto dentro como fuera de los Estados Unidos; contrarrestar el antinorteamericanismo suscitado en casi todo el mundo por la prepotencia y la brutalidad de la oligarquía norteamericana, y situar a la filosofía norteamericana a la altura intelectual de la europea con una ligera ventaja para aquélla: su compromiso consustancial con la democracia. De este modo, Rorty resulta ser una nacionalista convicto y confeso, con el matiz de que su método es la persuasión y no la fuerza.

Una diferencia fundamental entre Rorty y sus clásicos es que éstos discutían con una Europa que venía siendo siendo la sede del Imperio desde el Romano hasta el Inglés. Y de la Cultura Imperial. Mientras que Rorty escribe desde la consciencia del desplazamiento de la potencia y la cultura imperiales de Europa a Norteamérica. Por eso ha podido ser visto como la voz narcisista del academicismo norteamericano (R. Bernstein y C. West) o, peor aún, de la Sociedad Nordatlántica rica y postmoderna. La América Imperialista. De hecho, en la órbita que acabo de citar Rorty expresa el deseo de que una unión futura de Estados Unidos y Europa -que él imagina so-

${ }^{15}$ En mi libro, La construcción ética del otro, Oviedo, Nóbel, 1997, cap. 3.

${ }_{16}$ Ver el reciente R. Rorty, Forjar nuestro país, (Barcelona, Paidós, 1999), vers. cast. de Achieving Our Country, 1998. Una imagen más completa de Emerson puede verse en C. West, The American Evasion of Philosophy. A Genealogy of Pragmatism, Madison, University of Wisconsin Press, 1989, cap. 1. 
cialdemócrata, de izquierda reformista- llegue a formar una federación Noratlántica cuyo alcance político se extienda a todo el espacio de la globalización económica. A esta federación que margina olímpicamente a la ONU, la denomina Rorty «parlamento de la Humanidad».

\section{El núcleo teórico}

En lo que resta me gustaría tocar lo que me parece el núcleo teórico de la filosofía de Rorty: i) su compromiso axiológico o ético en torno al que gira todo lo demás; ii) su antifundamentalismo filosófico; ii) su método pragmático-conversacional contingente; iv) su articulación del espacio conversacional: a) dentro de las sociedades democráticas de cultura occidental en torno a la separación público/privado), y b) hacia fuera de estas sociedades -que hoy ya son multiculturales-, en relación con las no occidentales, bajo la figura de un etnocentrismo abierto.

Comenzaré por un texto de la Introducción a Contingencia, ironía y solidaridad (p. 17) en el que Rorty traza el retrato del «ironista liberal», la compleja figura que condensa todos los problemas que acabo de apuntar:

... los liberales son personas que los actos de crueldad son lo peor que se puede hacer. Empleo el término «ironista» para designar a esas personas que reconocela contingencia de sus creencias y de sus deseos más arraigados: personas lo bastante historicistas y nominalistas, para haber abandonado la idea de que esos deseos remiten a algo que está más allá del tiempo y del azar. Los ironistas liberales son personnas que entre esos deseos imposibles de fundamentar, incluyen sus propias esperanzas de que el sufrimiento ha de disminuir, que la humillación de los seres humanos por otros seres humanos ha de cesar (subrayado mío).

Este párrafo define al liberal por su compromiso axiológico, ético, constituído por: su creencia de que hay un «mal radical», la crueldad, humillación o sufrimiento innecesario de los seres humanos, y su apuesta decidida en su contra; la esperanza de que ese mal no sólo habrá de disminuir sino de desaparecer. Hay que añadir un tercer valor, que no aparece en este texto, pero que es la cara positiva de la crueldad: se trata de la solidaridad, que Rorty no entiende únicamente en términos de la «ayuda humanitaria» (aliviar el dolor orgánico, que los seres humanos compartimos con los demás animales), sino que se preocupa, sobre todo, por el daño más o menos irreparable, causado o que se puede causar, a la identidad de las personas. Este daño es la humillación, y constituye una forma de dolor especificamente humano, que no compartimos con los demás animales.

Hay -entre otros- un cuarto valor, que tampoco figura en el texto, y que nos desplaza ya a la parte ironista del liberal: se trata de la autocreación -concepto tomado de Foucault y Nietzsche-, la tarea de ser artista de la propia identidad vital: ser, pues, a la vez, el artista y la obra. A diferencia de la solidaridad, cuyo campo de cultivo es el espacio público, la autocreación 
ironista sólo puede cultivarse en privado. Es la separación público/privado que tanta crítica ha suscitado.

Pero ahora quiero centrarme en un rasgo de la identidad ironista que sí aparece en el texto: me refiero a la contigencia de sus creencias y deseos más arraigados, de los valores con los que está comprometido a muerte. Se trata del reconociniento filosófico de la imposibilidad de fundamentarlos. En otro texto del mismo libro (p. 91) Rorty presenta al ironista como un anti-fundamentalista radical. Escribe:

Llamaré «ironista» a la persona que reuna estas tres condiciones: 1) tenga dudas radicales y permanentes acerca del léxico último que utiliza habitualmente, porque han incidido en él otros léxicos, léxicos que consideran últimos las personas que ha conocido; 2 ) advierte que un argumento formulado con su léxico actual no puede ni consolidar ni eliminar esas dudas; 3 ) en la medida en que filosofa acerca de su situación, no piensa que su léxico se halle más cerca de la realidad que los otros o que esté en contacto con un poder distinto de élla misma. Los ironistas propensos a filosofar no conciben la elección entre léxicos ni como hecha dentro de un metaléxico neutral y universal ni como un intento de ganarse un camino a lo real que esté más allá de las apariencias, sino simplemente como un modo de enfrentar lo nuevo con lo viejo (subrayados míos).

Resumiendo: el ironista se identifica por sus dudas radicales acerca de su léxico último: aquel en el que expresa los valores con los que se compromete (hasta morir: Rorty sigue a Dewey en ésto), y por el reconocimiento de su incapacidad para remediarlas. Esta incapacidad surge de su increencia en un ámbito de validez metalingüística universal -llámese Metafísica en el sentido amplio del término: incluida la teología, o Razón, incluída la pragmática transcedental-, aquel tipo de lenguaje que pudiera oficiar de «espejo de la naturaleza». Por contra, el ironista está convencido de la contingencia radical del lenguaje. No sólo por su pluralismo etnocéntrico, sino también por su condición originariamente metafórica, por la imposibilidad de una relación necesaria entre el lenguaje y una realidad exterior y anterior (pasada), como la definida por la teoría clásica de la verdad como correspondencia.

Las consecuencias de este antifundamentalismo radical son, entre otras, las siguientes.

Extensión de la contingencia del lenguaje al yo y a la comunidad. De donde emerge una imagen postmetafísica del hombre y su mundo social a la que si conviene alguna denominación es la de democrática. No como descripción de cómo son las cosas hoy, sino de cómo pueden ser en el futuro que es el que, en fin de cuentas, inspira la visión pragmatista del significado a partir de Peirce: el espectro de significados hipotéticos o versímiles que el uso de los signos podría producir en nuestra conducta.

Imposibilidad de un razonamiento concluyente a partir de una premisa incondicionada que oficie de fundamento último. Este método se sustituye 
por la analogía o comparación que, en el léxico de Rorty, se denomina «redefinición» o «recontextualización» ${ }^{17}$. Imposibilidad, por lo tanto, de un razonamiento concluyente a la hora de elegir una ética, incluídos los derechos humanos. Lo único que cabe aquí es un compromiso como el que define al liberal: un compromiso autoconsciente de su carencia de fundamento racional. La única ráiz de la ética es, en la tradición de los sentimientos morales -la simpatía de Hume, a quien menciona explícitamente, pero no a Rousseau y su compasión/piedad-. Aunque, en su caso, el sentimiento moral básico es la sensibilidad hacia el dolor y la humillación de los otros ${ }^{18}$.

Prioridad de la democracia sobre la filosofía. La democracia no se fundamenta en nada anterior, exterior o más poderoso que élla misma y los compromisos axiológicos de sus miembros. La filosofía es un método de autorreflexión de la democracia sobre sí misma mediante la conversación dialógica, que es la que forma y reforma las identidades democráticas ${ }^{19}$. Y etnocentrismo. Toda conversación está situada en el algún punto del espacio-tiempo: luego es radicalmente etnocéntrica o etnocentrada (no necesariamente etnocentrista). El etnocentrismo rortyano tiene, entonces, la intención de no convertir el propio etnos o la propia parroquia en «la humanidad universal» a la que tan propensa ha sido la filosofía europea clásica desde el primer capítulo de la Política de Aristóteles, que identificaba la identidad humana con la identidad de los atenienses varones, adultos y libres. En todo caso, el etnocentrismo de Rorty está mediatizado por la solidaridad: la preocupación por el daño a la identidad de los otros, a quienes se trata de convertir en «uno de los nuestros». Y de definir nuestro propio etnos como el de aquellos que dudan de su propio etnocentrismo: de si es suficientemente sensible ante el dolor y la humillación de los otros ${ }^{20}$. Con posterioridad, ante la crítica de C. Geertz, Rorty parece haber reafirmado un tanto su compromiso etnocéntrico al sostener que está bien que vivamos en un bazar kuwaití, siempre que subsista algún club privado donde cada uno pueda retirarse a reencontrar, con los suyos, sus propias raíces ${ }^{21}$.

${ }^{17}$ Cfr. La filosofgía y el espejo.... cit., cap. VIII, y «La indagación como recontextualización», en Objetividad, relativismo y verdad, cit.

18 «Human Rights, Rationality and Sentimentality», en Truth and Progress. Philosophical Papers. 3, cit.

${ }^{19}$ Cfr. «La prioridad de la democracia sobre la filosofía», en Objetividad..., cit.

20 Contingencia, ironía..., cit., p. 216.

${ }^{21}$ Cfr. «Sobre el etnocentrismo: respuesta a Clifford Geertz», en Objetividad..., cit., p. 283. El trabajo de Geertz que tiene en cuenta Rorty, «Los usos de la diversidad» de 1984, está incluído en el vol. (al que da nombre) Los usos de la diversidad, Barcelona, Paidós, 1999.

\section{DOXA 23 (2000)}

